\title{
Development of a Radar Reflector Kit for Older Adults to Use to Signal Their Location and Needs in a Large-Scale Earthquake Disaster
}

\author{
Yuma Morisaki ${ }^{1}$, Makoto Fujiu ${ }^{2, *}$, Ryoichi Furuta ${ }^{3}$ and Junichi Takayama ${ }^{4}$ \\ 1 Division of Environmental Design, Graduate School of Natural Science and Technology, \\ Kanazawa University, Kanazawa 920-1192, Japan; yki20@stu.kanazawa-u.ac.jp \\ 2 Faculty of Transdisciplinary Sciences, Institute of Transdisciplinary Sciences, Kanazawa University, \\ Kanazawa 920-1192, Japan \\ 3 Remote Sensing Technology Center of Japan, Minato, Tokyo 105-0001, Japan; furuta_ryoichi@restec.or.jp \\ 4 Kanazawa University, Kanazawa 920-1192, Japan; takayama-j@staff.kanazawa-u.ac.jp \\ * Correspondence: fujiu@se.kanazawa-u.ac.jp; Tel.: +81-76-234-4914
}

Citation: Morisaki, Y.; Fujiu, M.; Furuta, R.; Takayama, J. Development of a Radar Reflector Kit for Older Adults to Use to Signal Their Location and Needs in a Large-Scale Earthquake Disaster. Remote Sens. 2021, 13, 1883. https://doi.org/ $10.3390 / \mathrm{rs} 13101883$

Academic Editor: Addabbo Pia

Received: 4 April 2021

Accepted: 7 May 2021

Published: 11 May 2021

Publisher's Note: MDPI stays neutral with regard to jurisdictional claims in published maps and institutional affiliations.

Copyright: (c) 2021 by the authors. Licensee MDPI, Basel, Switzerland. This article is an open access article distributed under the terms and conditions of the Creative Commons Attribution (CC BY) license (https:// creativecommons.org/licenses/by/ $4.0 /)$.

\begin{abstract}
In Japan, older adults account for the highest proportion of the population of any country in the world. When large-scale earthquake disasters strike, large numbers of casualties are known to particularly occur among seniors. Many are physically or mentally vulnerable and require assistance during the different phases of disaster response, including rescue, evacuation, and living in an evacuation center. However, the growing number of older adults has made it difficult, after a disaster, to quickly gather information on their locations and assess their needs. The authors are developing a proposal to enable vulnerable people to signal their location and needs in the aftermath of a disaster to response teams by deploying radar reflectors that can be detected in synthetic aperture radar (SAR) satellite imagery. The purpose of this study was to develop a radar reflector kit that seniors could easily assemble in order to make this proposal feasible in practice. Three versions of the reflector were tested for detectability, and a sample of older adults was asked to assemble the kits and provide feedback regarding problems they encountered and regarding their interest in using the reflectors in the event of a large-scale disaster.
\end{abstract}

Keywords: large-scale earthquake disaster; older adults; ascertaining location and needs; questionnaire survey

\section{Background and Purpose \\ 1.1. Background}

The proportion of the population accounted for by people aged 65 and older is higher in Japan than in any other country in the world. As shown in Figure 1, in 2018, it was 28.1\%. Even compared with other developed countries, which, globally, have relatively high population aging rates, Japan's aging rate is markedly higher [1]. When a society ages, the accompanying decline in the relative size of labor force may slow economic growth, which increases the risk that the economic balance on which social security (the social welfare and healthcare systems) depends may collapse. Another challenge Japan has is that it is at risk for a variety of natural disasters due to its location, topography, geology, climate and other natural features. Over the past few years, several earthquake disasters have occurred, including the 2011 Tohoku-Pacific Ocean Earthquake, the 2016 Kumamoto Earthquake, and the 2018 Hokkaido Eastern Iburi Earthquake. When an earthquake disaster occurs in Japan, one of the major problems is the large number of older people among the victims. Although it depends on the individual, both physical and mental functioning tend to begin to decline after age 65 . When afflicted by a disaster at an older age, in many cases third-party assistance is needed during the different phases of disaster response, including 
rescue, evacuation, and living in an evacuation center. As already mentioned, given the certainty that Japan's population will continue to age, establishing disaster prevention measures focused on the welfare of older adults is an urgent issue.

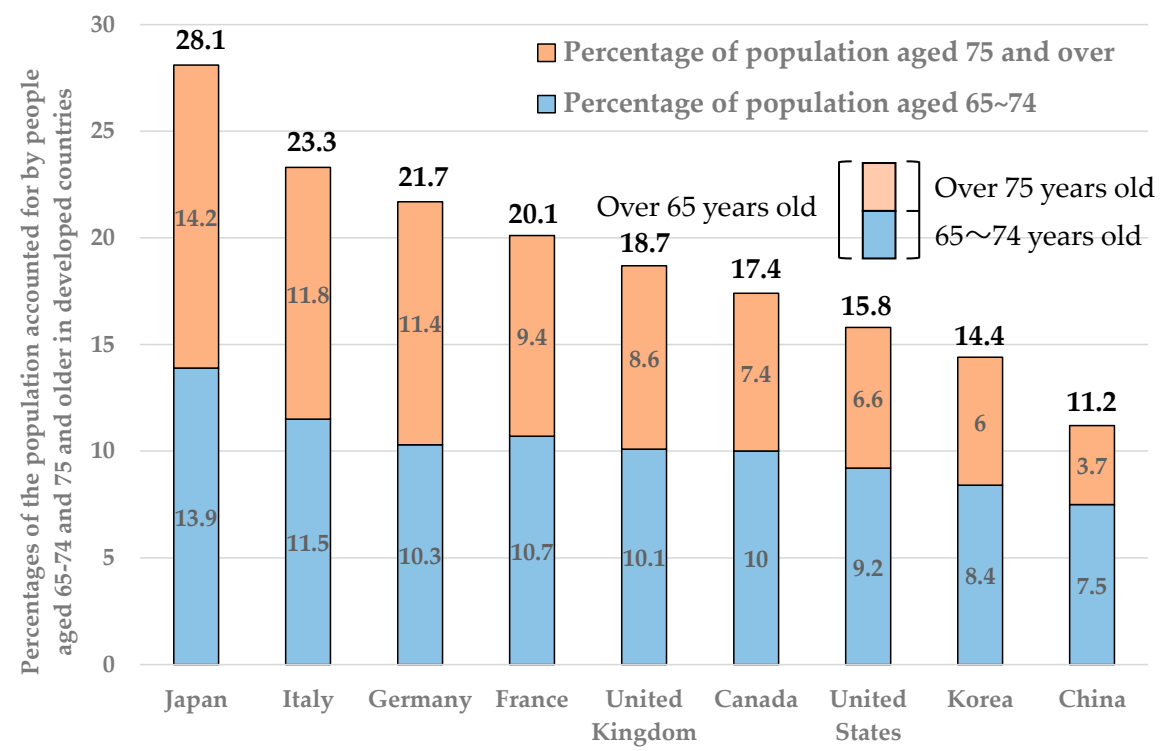

Figure 1. Percentages of the population accounted for by people aged 65-74, and 75 and older in developed countries in 2018.

One of the support systems for the elderly already in place in Japan is the system of Registries of Individuals Needing Evacuation Assistance [2]. These are local registries that list individuals who would have difficulty evacuating on their own at the time of a disaster. These started to be created after the 2011 Tohoku-Pacific Ocean Earthquake in 2011. Assistance is to be provided based on information in the registry, which includes whether the person needs long-term care or disability assistance, whether the person lives with other family members, and whether the person registered any specific requests. Although the registry identifies anyone who may not be able to evacuate on their own (not only older people), people 65 and older account for most of those registered. For people in the registry, their address, medical conditions, and other information are disclosed mainly to municipal staff who provide disaster assistance. Unfortunately, an enormous number of older Japanese remain unregistered. When the next large-scale disaster strikes, information on the locations and needs of these people will not yet have been gathered.

\subsection{Purpose}

We have already proposed an innovative way to ascertain the location and needs of older people in the aftermath of an earthquake disaster [3,4]. The method uses satellite images acquired via synthetic aperture radar (SAR). In our previous study, we proposed several types of radar reflectors that are detectable in SAR satellite imaging and have different backscattering coefficients (indicating the level of reflectivity) (Figure 2). The reflectors are composed of aluminum, and different numbers of partitions are used to give them distinctive shapes. The process used by the victim to alert response teams to their location and needs is shown in Figure 3. In the event of a large-scale disaster, the victim sets up a reflector for the satellite to observe as its radar gathers data on the Earth's surface. The location of the reflector (and the disaster victim) can be identified from the SAR images. The victim's needs can be conveyed by the type of reflector the victim chooses to set up. Reflectors with different numbers of partitions have discrete backscattering coefficients. As a result, determining the correspondence between the need to be communicated and backscattering coefficient (reflector type) beforehand allows a response team to differentiate between needs according to the type of reflector deployed by the victim. 


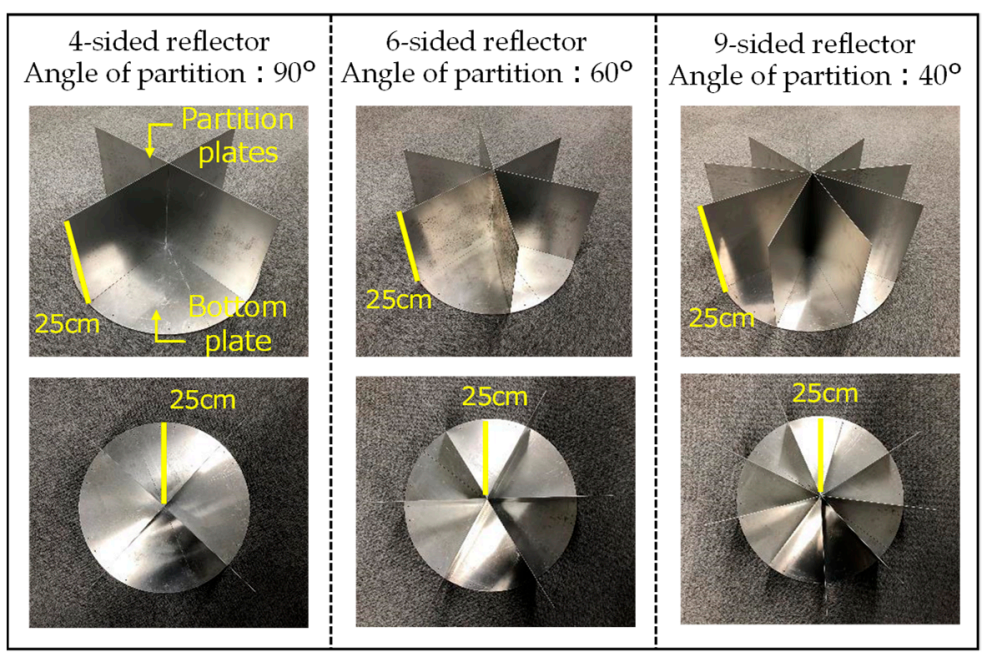

Figure 2. Reflector types.

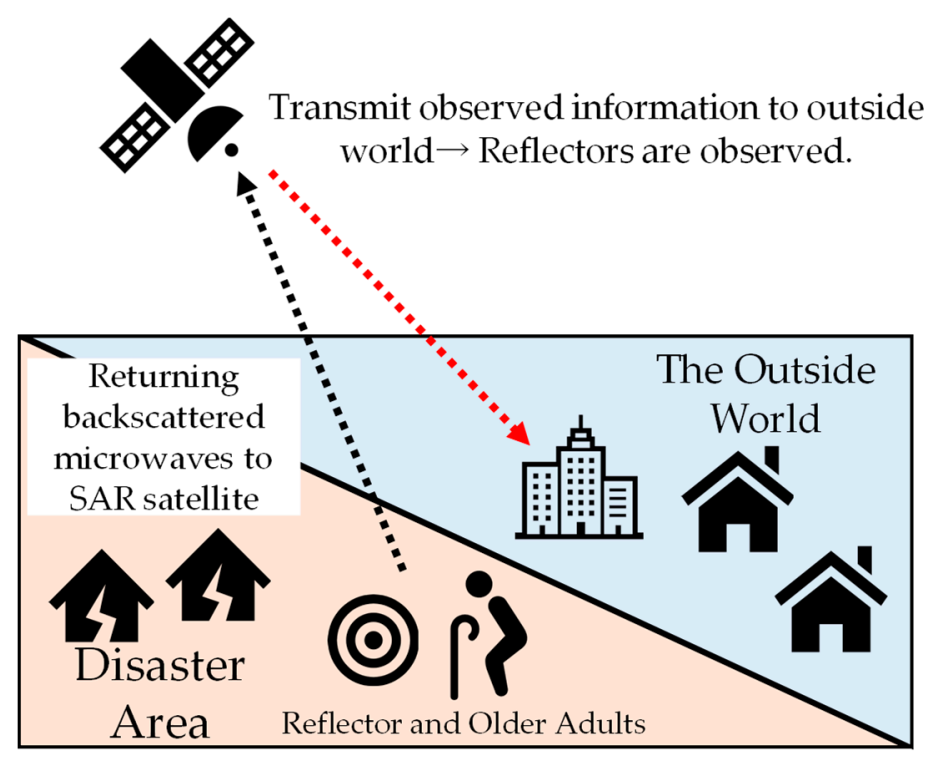

Figure 3. The signaling concept.

The reflectors we have created for this proposal have all been made from sheets of aluminum. For this study, based on those designs, we developed a reflector assembly kit that is compact enough to be easily storable. One of the purposes of this study was to have a sample of people 65 and over actually assemble kits for each of the reflector types and obtain feedback about the kit and any problems they had while assembling them. The other was to confirm that the reflectors made from the kits were detectable and that their backscattering coefficients were discrete. In this study, feedback survey was conducted regarding the ease of kit assembly and participant interest in using these radar reflectors in the event of a major disaster from a sample of older adults. Furthermore, multiple experiments to set- up reflectors were conducted to ascertain what kinds of backscattering coefficients would be obtained. The above two points are the main purpose of this study, and the outline of the feedback survey and experiment will be described later. 


\section{Literature Review and Justification for the Study}

\subsection{Literature Review}

In this section, we review previous studies that used SAR satellites in the aftermath of earthquake disasters and studies for using reflectors that could be detected in SAR satellite imaging.

Numerous studies have been conducted on the use of SAR satellites in the event of an earthquake disaster in many fields focusing on damage assessment. For example, Miura et al. [5] used SAR images to assess damage to buildings after an earthquake disaster. In addition, Hasekura et al. [6] proposed a method for determining areas that sustained building damage in the 2011 Tohoku-Pacific Ocean Earthquake. Both of these studies focused on building damage and its assessment, as opposed to ascertaining the location and needs of vulnerable individuals, as in the present study. Furthermore, many studies have been conducted regarding landslide situations during earthquake disasters, for example, Sato et al. [7], Li et al. [8] and so on.

Studies of proposals involving the creation of radar reflectors for use in combination with a SAR satellite include those by Takahashi et al. [9] and Suzuki [10]. The first involved creating a simple reflector that could be assembled by children and would be detectable by a SAR satellite in order to stimulate children's interest in satellites used to observe the Earth. The second study concerned the use of reflectors to create geoglyphs. The reflectors made in these studies were like the basic triangular and corner reflectors seen in remote-sensing reference books. In other words, the uses for the reflectors in those studies were unrelated to their use in our proposal, so fundamental differences were evident. Studies utilizing corner reflectors have been conducted, for example, by Jauvin et al. [11] and Schmidt et al. [12] However, these also have a different perspective from this study.

Thus, reviewing the literature for studies using SAR satellites from these two perspectives showed that our proposal contributes to the field in two ways. No previous studies using SAR satellites have attempted, as proposed in this study, to develop reflectors for use with satellites in earthquake disasters. In addition, in regard to the proposals of Takahashi et al. [9] and Suzuki [10], the review showed that our proposal is innovative in its concept of developing a kit for assembling a radar reflector, so that it could be put to practical use, in this case, in the event of a disaster.

\subsection{Justification for the Study}

Recent Japanese research into tools that can be used by disaster victims in disaster areas to transmit information to the outside world has used devices such as mobile phones [13-15]. These approaches have made it relatively easy for victims to alert others to their needs and for disaster response teams to gather that information. However, in a large-scale disaster, there is a good chance that the base stations that transmit communications would be damaged, disrupting communications over broad areas. Moreover, although some scenarios have victims using Twitter and other SNS platforms to send out information, this would depend on the same communications networks being functional. While there are other methods for gathering this information, such as fire brigades intensely patrolling affected areas (a tactic referred to as the "human wave attack"), or using high-altitude cameras or helicopters [16], shortages of available personnel would be a concern. Further, other issues are that the ranges that these methods can cover are extremely small and the information gathered may not be sufficiently detailed or accurate. In the past few years, drones have often been used to collect information during earthquake disasters. However, similar to the issues with using aerial photos taken from helicopters, they only cover a limited area, and while they may be very useful for monitoring conditions in the disaster area, drones would be difficult to use to assess the situations and needs of individual victims.

The proposal being developed in this study assumes the occurrence of a large-scale earthquake disaster in which damage is widespread and communications have been disrupted. The objective is to make a tool that can be used to communicate with the outside world under such conditions because cell phones and other conventional devices cannot be 
used. Furthermore, although these experiments are being conducted in Japan, the approach is applicable to any location that can be observed by a SAR satellite, which we believe is anywhere in the world.

As demonstrated in the previous section, no previous studies have been conducted on the use of SAR-detectable reflectors by earthquake victims to signal their location and needs via satellite to response teams outside of the disaster area. Although the objective of locating victims and ascertaining their needs may be the same as in previous studies using existing tools for communication, the scale of disaster being assumed here differs. As a result, we believe that when comparing this proposal with those using existing tools, the situations/conditions in which this tool could be useful justify its development.

In the rest of this article, we will, first, briefly describe the reflector kit and how it is assembled (Section 3). Next, we will describe how we set up reflectors we had assembled at several locations in Kanazawa City in Ishikawa Prefecture to confirm their detectability and to determine the values of their backscattering coefficients (Section 4). After that, we describe how we asked a sample of older people to actually assemble kits to obtain feedback on what they thought about them and what they thought was problematic (Section 5).

\section{Reflector Kit Development}

\subsection{SAR Satellite Imagery Parameters}

This study used satellite images acquired by the SAR satellite ASNARO-2 [17], which is operated by the NEC Corporation. Table 1 shows the satellite's specifications and image performance parameters. The images used in this study were acquired in Spotlight mode, which uses a swath of $10 \mathrm{~km}$ and a spatial resolution of $1.0 \mathrm{~m}$ or less. Observations were carried out using HH-polarized X-band radar. The radar reflectors were, therefore, designed to be large enough to be detected by ASNARO-2 in Spotlight mode.

Table 1. ASNARO-2 Specifications/Image Performance Parameters [13].

\begin{tabular}{|c|c|}
\hline Launch & $\begin{array}{l}18 \text { January } 2018 \text { Launched by Epsilon Rocket } \\
\text { (JAPAN) }\end{array}$ \\
\hline Start of service & 3 September 2018 \\
\hline \multirow[t]{2}{*}{ Mass } & $570 \mathrm{~kg}$ \\
\hline & X-band Parabola SAR \\
\hline SAR sensor & 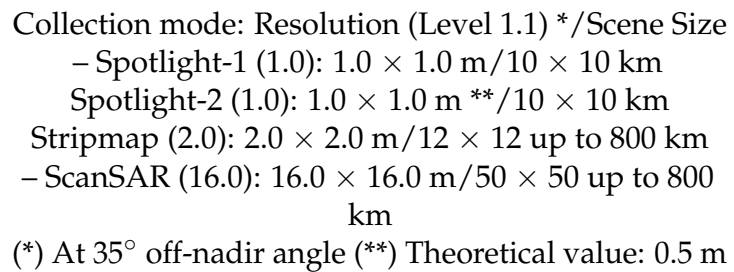 \\
\hline Orbit & $\begin{array}{l}\text { Sun Synchronous Orbit } \\
\text { Alt: Approx. } 500 \mathrm{~km}\end{array}$ \\
\hline
\end{tabular}

\subsection{The Reflector Kit and Its Assembly}

In our previous study, we proposed a reflector with the three different shapes shown in Figure 2. For simplicity, we refer to the three reflector types as 4-sided, 6-sided, and 9-sided. When determining the size and shape of reflectors to use, we kept in mind the following two points based on the findings of experts in remote sensing $[3,4]$ :

1. Given that the reflector would be set up by a disaster victim, the size of the reflector needed to be as small as possible but still detectable in ASNARO-2 imagery.

2. To make set-up as easy as possible, the shape of the reflector should make it detectable regardless of the direction of the satellite's orbit during observations.

The reflectors shown in Figure 2 were crafted by hand from aluminum sheets taking these two points into account. For this study, we developed a reflector kit that could be easily 
assembled into reflectors of similar size and shape. The reflector assembly kit is shown in Figures 4-7. First, as shown in Figure 4, the kit (which weighs $2.9 \mathrm{~kg}$ ) consists of (1) the bottom plate, (2) top and bottom corner latches, and (3) nine partition plates. The bottom plate has a diameter of $50 \mathrm{~cm}$, is $3.0 \mathrm{~mm}$ thick, and is split into two half-plates. In the center is a large hole into which one of the large corner latches (depending on the number of plates to be used) is snapped into place. Around the center and the outside edge are small holes into which the partition plates snap into place. The small holes around the outside edge are color-coded to indicate which should be used depending on whether a 4-sided (red), 6-sided (yellow), or 9-sided (blue) reflector is being assembled (Figure 5). The underside of each type of corner latch has the same color coding (Figure 6). There are two corner latches: one large and one small for each type of reflector. For example, for the 4 -sided reflector the 2 red (top and bottom) latches are used. They each have slits in the surface that hold the bottom and top inner corners of each partition plate in place. Figure 7 shows one of the partition plates (3). They are $25 \mathrm{~cm}$ square and $1.0 \mathrm{~mm}$ thick. At two places along the bottom edge are prongs that snap into holes in the bottom plate.

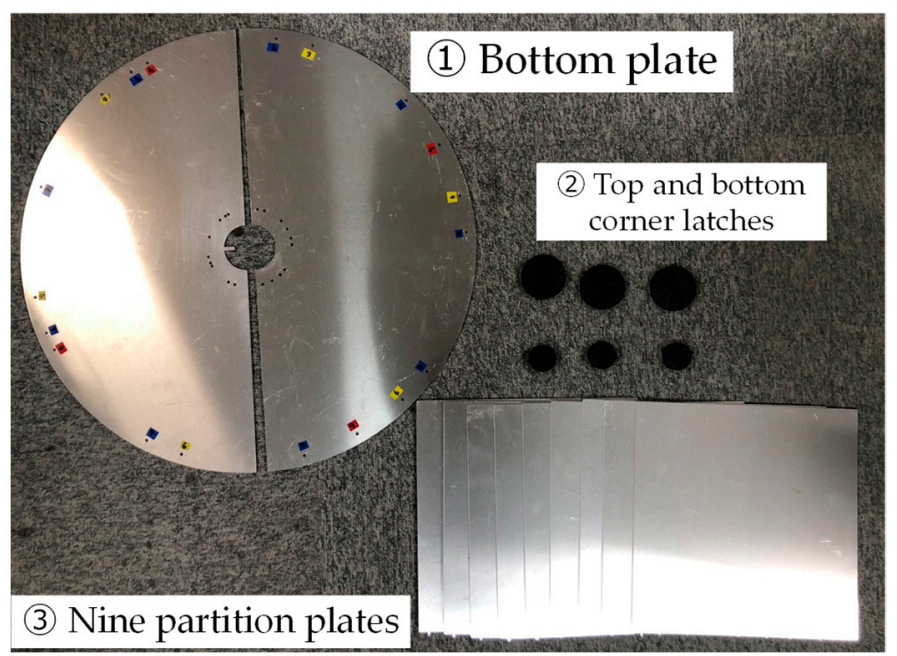

Figure 4. The reflector kit.

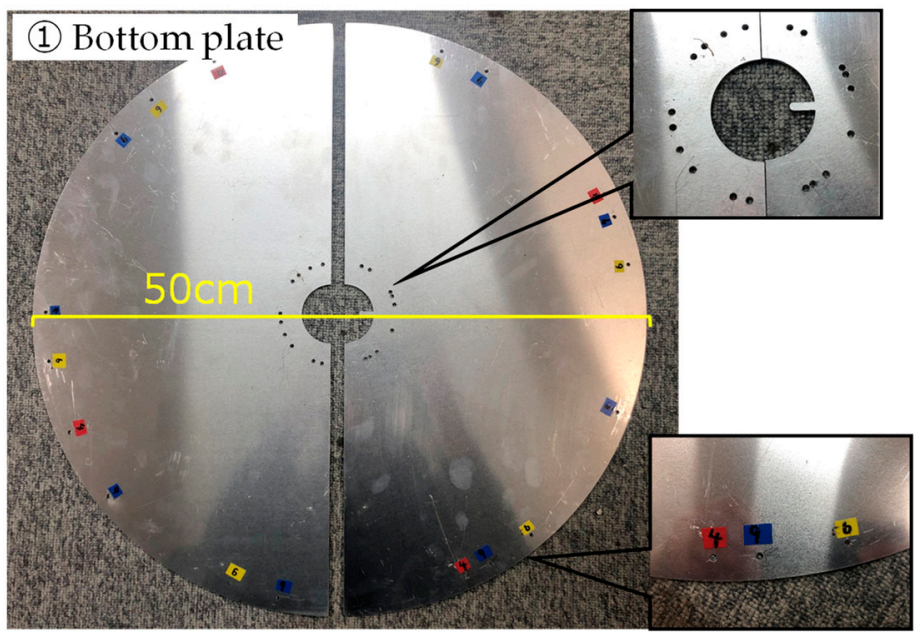

Figure 5. Reflector kit (1) Bottom plate. 


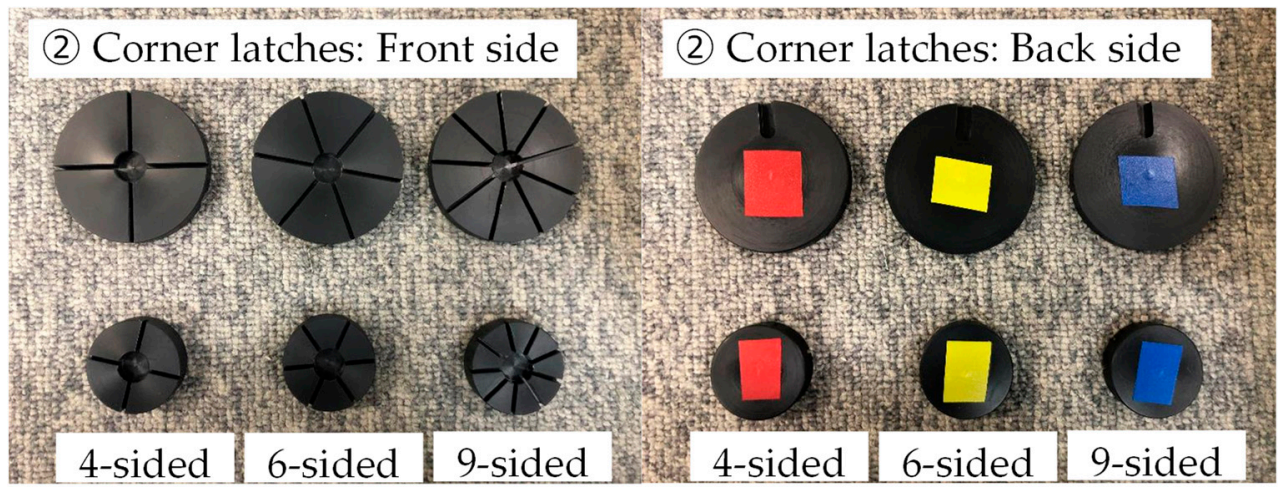

Figure 6. Reflector kit (2) Corner latches.

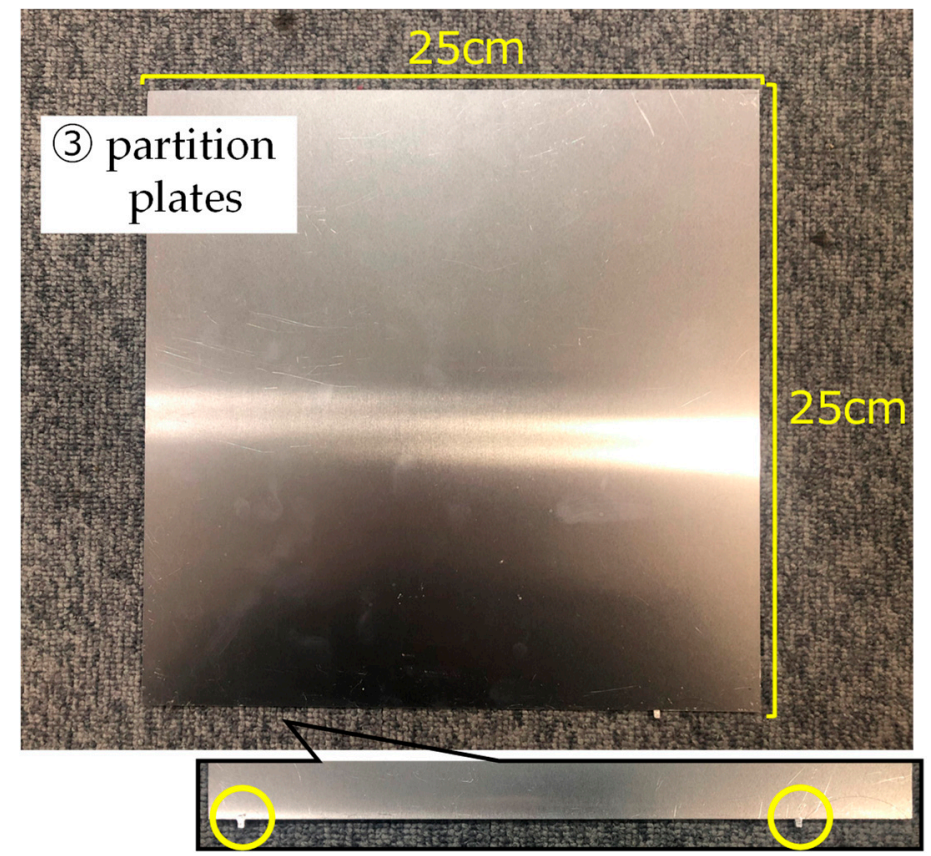

Figure 7. Reflector kit (3) Partition plate.

Figure 8 shows the 4-step assembly procedure. Step 1: Snap the large corner latch (2) corresponding to the type of reflector being made into the large hole in the center of the bottom plate (1) to hold the two half-plates together, slits facing up. Step 2: Snap the partition plates into place by fitting the prongs on the bottom edge into the small holes in the bottom plate and slipping the inner bottom corner into the slit in the corner latch. Repeat for the rest of the partition plates needed for the desired reflector form. Step 3: Find the small corner latch (2) corresponding to the reflector being made. Step 4: Snap the slits of the small corner latch (2) into place over the upper inner corners of the partition plates (3) to lock them into place. The 4-, 6-, and 9-sided reflectors are all assembled following this same procedure. 

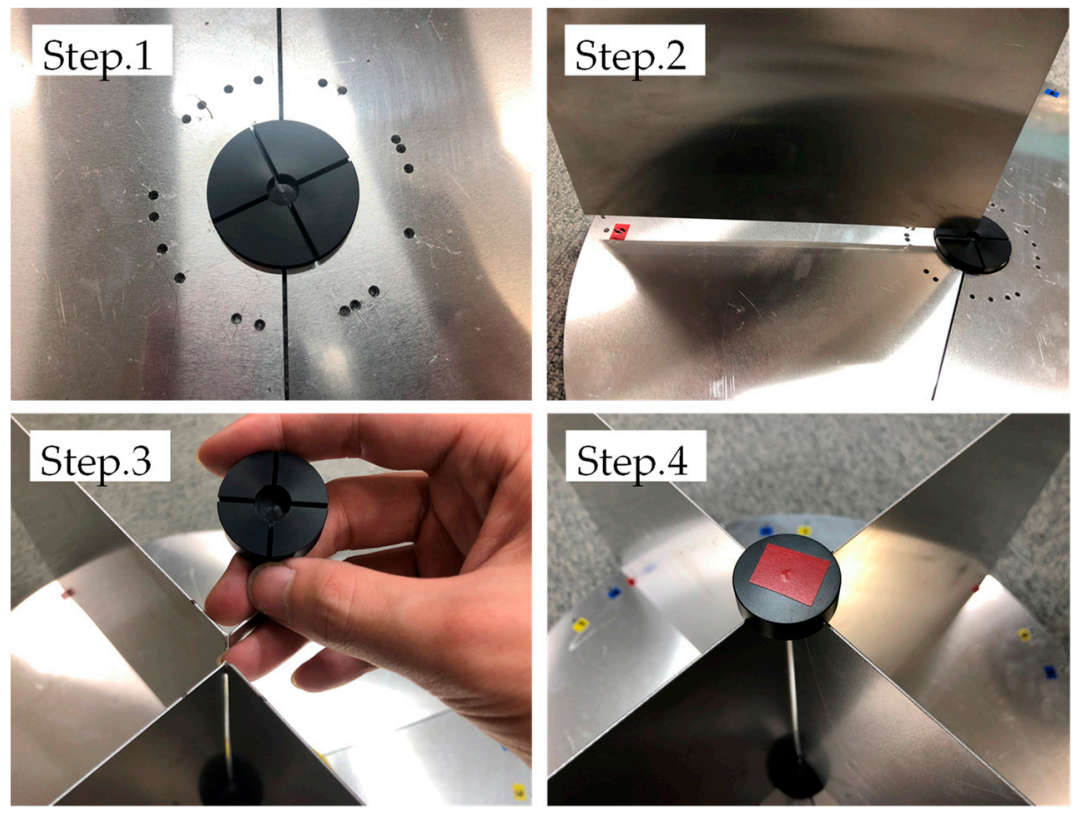

Figure 8. Reflector kit assembly steps.

Next, we will describe how we confirmed that these newly developed reflectors were detectable by ASNARO-2 and discuss feedback obtained from a sample of older adults who tested the assembly of the kits.

\section{Reflector Detectability in ASNARO-2 Imagery}

\subsection{Testing the Reflector Kit Set-Up}

We set up a number of these reflectors around the city of Kanazawa in Ishikawa Prefecture, the site for the study. In a previous study, we had confirmed that, in ideal conditions such as flat open ground, each reflector has a distinctive backscattering coefficient [3]. For the present study, to imitate what the actual set-up conditions would be, we set up reflectors all over Kanazawa to ascertain what kinds of backscattering coefficients would be obtained.

Kanazawa, the study site, is located on the Sea of Japan in the center of the Japanese archipelago and is the capital of Ishikawa Prefecture (Figure 9). It covers an area of 468.64 $\mathrm{km}^{2}$, and as of December 1, 2020, it had a population of 450,945 people (of which $26.8 \%$ were aged 65 or older) in 209,498 households [18]. As shown in Table 1, the ASNARO-2 Spotlight mode makes observations in $10 \mathrm{~km}$ swaths. Observations were conducted multiple times of the area around Kanazawa University. Twenty reflectors (eight 4-sided, six 6-sided, and six 9-sided reflectors) were placed in locations around the city where permission to do so could be attained. Those places were mainly along roadsides and walkways or in parks and other green spaces. ASNARO-2 made observations on 3 days in 2020: on May 26 (ascending orbit), May 28 (descending orbit), and July 7 (ascending orbit). Figure 10 shows the locations of each reflector type and the swaths observed during the ascending and descending orbits. Reflectors were located some places such as roadsides and walkways or in parks and other green spaces to compare the surface condition and results. 


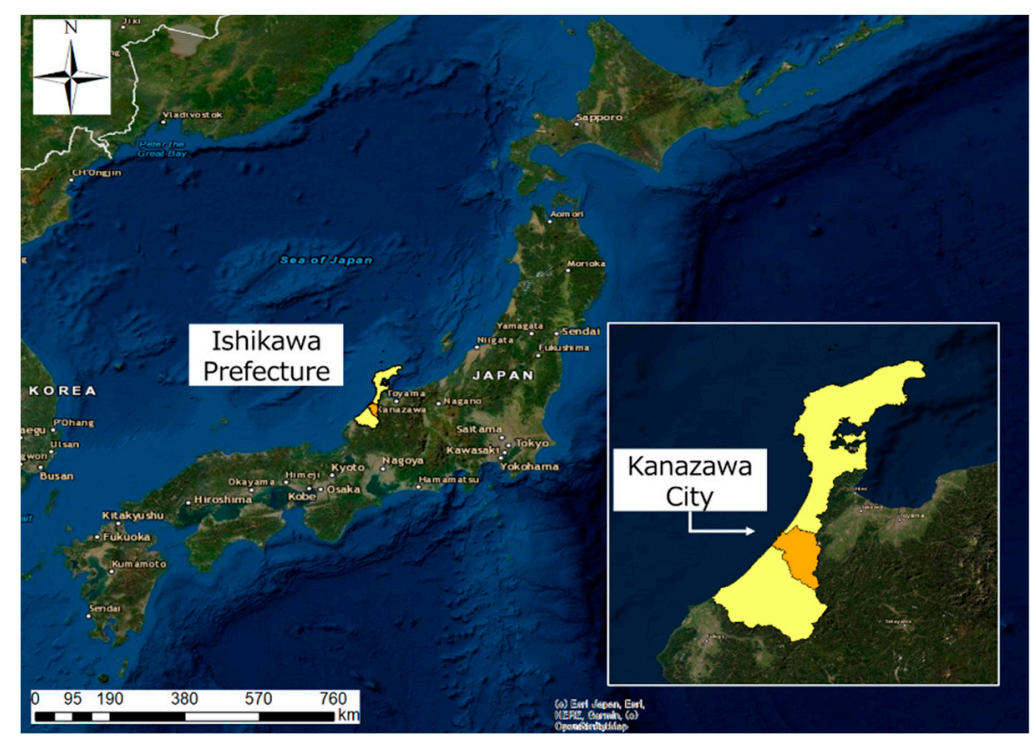

Figure 9. The locations of Kanazawa City.

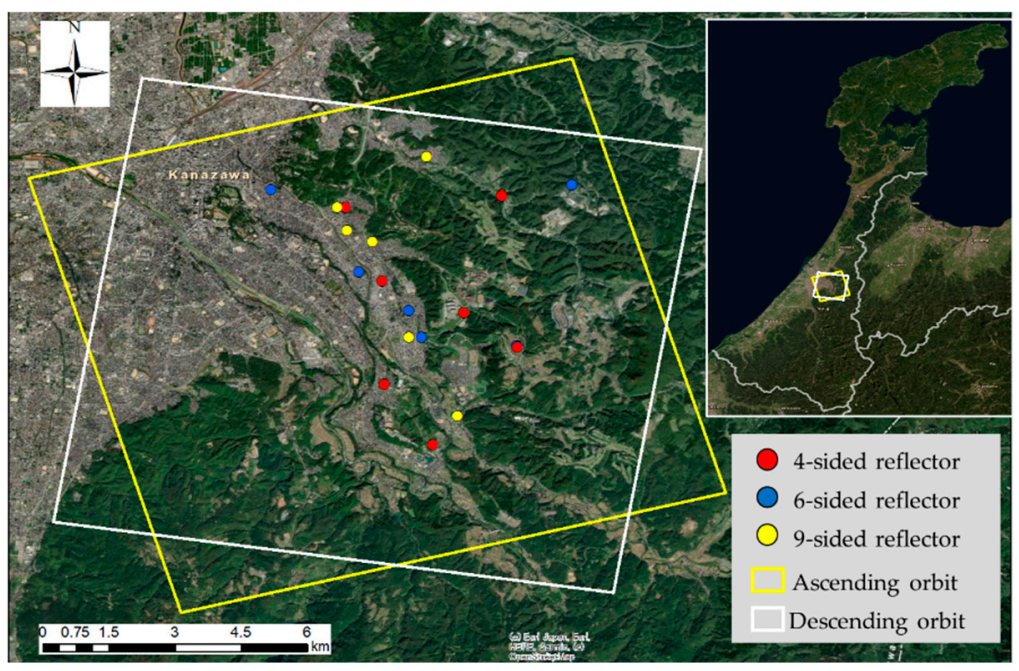

Figure 10. Observed swaths and reflector locations by reflector type.

\subsection{Determining Reflector Detectability and Backscattering Coefficients}

The backscattering coefficient $\sigma^{0}$ was calculated using the following Formula (1). The calculation uses SAR images after orthorectification.

$$
\sigma^{0}=10 \cdot \log _{10}\left\langle I^{2}+Q^{2}\right\rangle+C F
$$

Here, $\sigma^{0}$ is the backscattering coefficient (in $\mathrm{dB}$ ), $I$ and $Q$ are the numbers of pixels in the SAR data, and CF is the correlation constant. To identify the locations of the reflectors in the SAR images, we used the location we noted when setting them up.

Figure 11 shows what the reflectors looked like in the ASNARO-2 images. As already mentioned, we set up 20 reflectors, but due to space limitations here, the figure shows just one example for each reflector type. For comparison, each image is shown with another image of the same location dated June 9 (ascending orbit) or June 10 (descending orbit), days when the reflectors were not deployed. The figure clearly shows that each type of reflector can potentially be seen in the SAR images. That said, of the 20 reflectors set up, some went undetected (Figure 12). While all of the 9-sided reflectors were detected, of the eight 4 -sided reflectors only six $(75 \%)$ were detected, and of the six 6 -sided reflectors only three (50\%) were detected. Table 2 shows details of set-up places. Mainly, roadsides, 
walkways, in parks and other green spaces were used. The 6-sided reflectors were not visible at two places such as park or green places. The 4-sided reflectors were not visible roadside (two places). The fact that two 4-sided and three 6-sided reflectors were not visible in the images was likely due to significant SAR shadowing caused by large objects such as buildings and trees blocking the signal from reaching those reflectors.

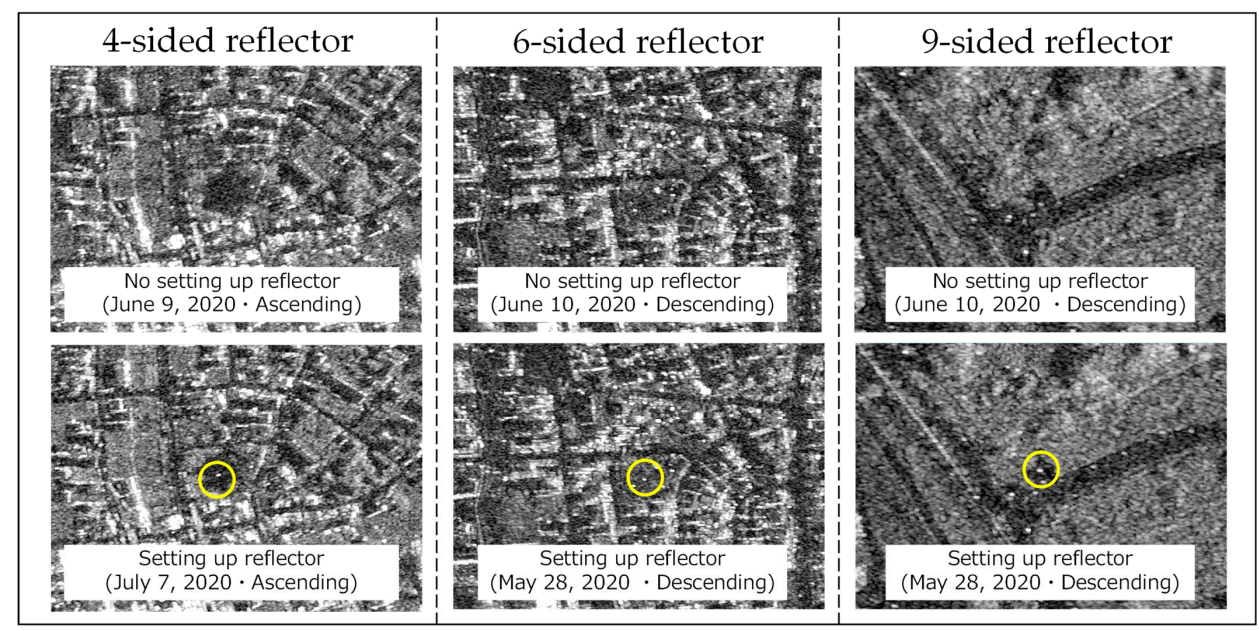

Figure 11. Evidence of the detectability of each reflector type in ASNARO-2 images.

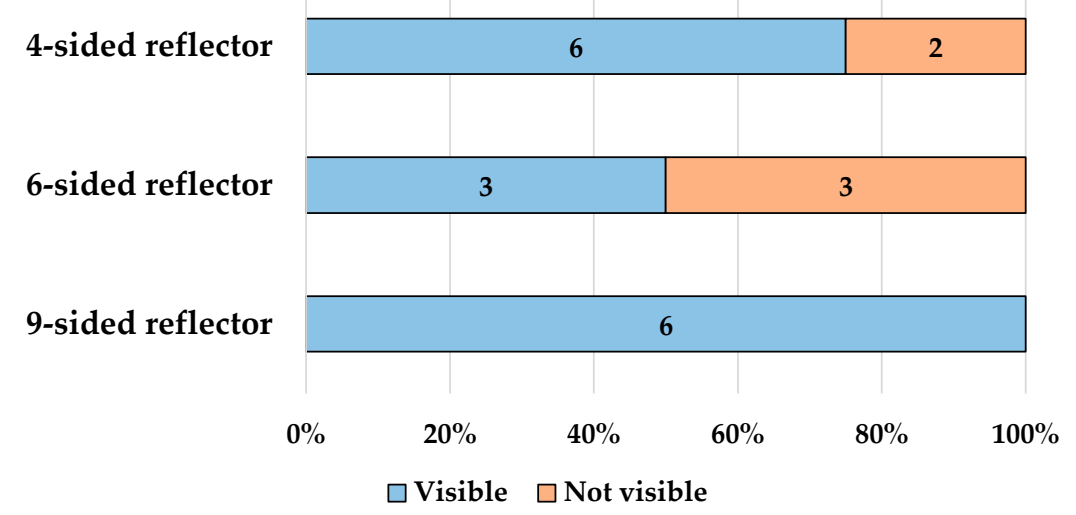

Figure 12. Detectability by reflector type.

Table 2. Details of set-up places.

\begin{tabular}{lccc}
\hline & $\begin{array}{c}\text { In the Park or } \\
\text { Greenspace }\end{array}$ & Walkways & Roadside \\
\hline 4-sided reflector & 2 & 3 & 3 \\
\hline 6-sided reflector & 4 & 1 & 1 \\
\hline 9-sided reflector & 2 & 1 & 3 \\
\hline
\end{tabular}

Figure 13 shows the means and standard deviations for the backscattering coefficients by reflector type for the reflectors that were detected. The 4-sided reflectors had the highest mean at $14.3 \mathrm{~dB}$, followed by the 6-sided reflectors, with the coefficients for the 9-sided reflector being the smallest. Even taking the standard deviations into consideration, there was almost no overlap between reflector types in values for their backscattering coefficients. There was no overlap at all between $\sigma^{0}$ values for the 6- and 9-sided or between the 4- and 9 -sided reflectors. There was only a very slight overlap of $0.3 \mathrm{~dB}$ between the 4 -sided and 6-sided types. These results confirmed that when victims set up a reflector, because there 
is by and large almost no overlap in the backscatter coefficients for the different reflector types, the type of reflector deployed should be identifiable.

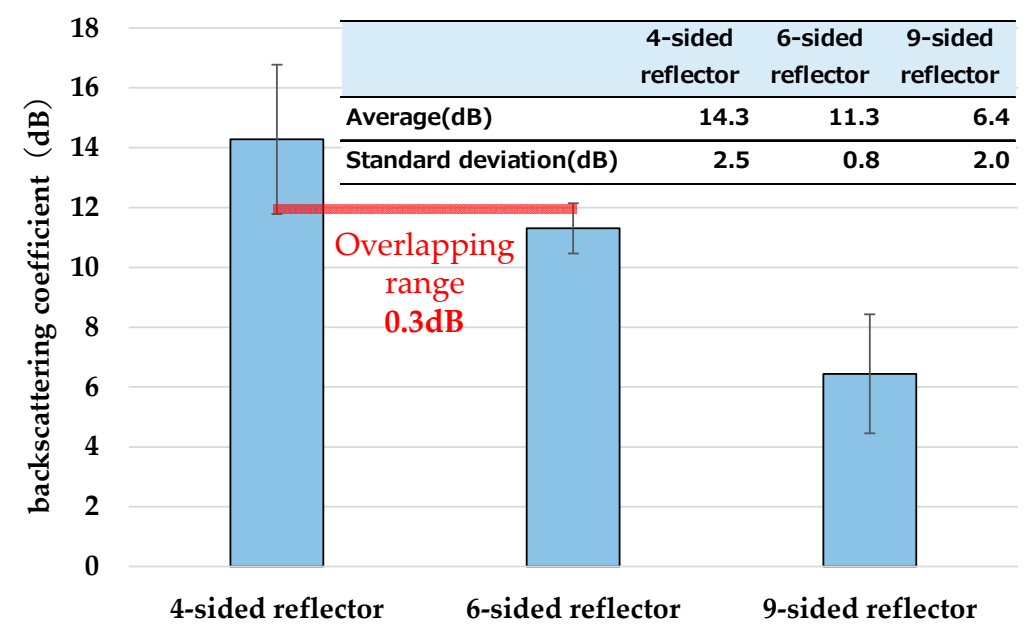

Figure 13. Mean $\sigma^{0}$ and SD by reflector type.

\section{Radar Reflector Kit Feedback Survey}

\subsection{Survey Items and Data Collection}

We gathered feedback regarding the ease of kit assembly and participant interest in using these radar reflectors in the event of a major disaster from a sample of 15 older adults who consented to participate in the study. On December 9, 14, and 16, 2020, we visited them in their homes to have them actually assemble each of the reflectors (Figure 14). Afterwards, we asked them to complete a survey that asked for some basic personal information, feedback regarding the assembly of the kit, and their opinions regarding their interest in using the reflectors in the event of an earthquake disaster, and we asked them to return it to us by mail. The survey results reported here were based on 10 surveys that were returned. Although the sample was very small, the reality is that, in any case, it would have been difficult to obtain a very large sample, given how much time and effort was involved in assembling the kits. The survey items are shown in Table 3. In addition to personal characteristics (age, gender, number of people in their household, medical conditions, and whether they were going for outpatient treatment), we asked for feedback regarding their experience assembling the three reflector types (ease of use, what exactly was difficult), how interested they would be in using a reflector should the occasion arise, and what information they thought they might need to signal to response teams outside the disaster area.

\subsection{Survey Results}

Table 4 shows the demographic factors and medical conditions for each of the 10 survey respondents. By age group, there were 2 respondents between the ages of 60 and 64,3 between 65 and 69, and 5 aged 70 or older. (Although Section 1 states that this study targets older adults 65 and older, in order to obtain more participants for the sample we included people aged 60-64). There were six men and four women. Four lived just with their spouse, and six lived with children and/or grandchildren. Eight of the 10 had some kind of medical condition, and all of them were receiving outpatient treatment. Details on their conditions are listed in the table. The majority went for outpatient treatment just once a month or once every 2 months (indicated in the table as 0.5 times/month). 


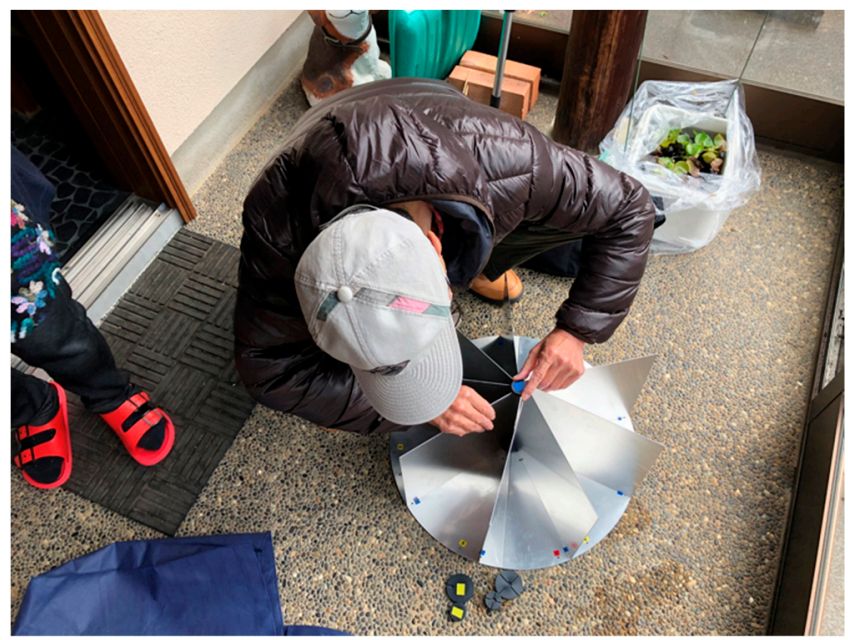

Figure 14. Participant assembling a kit.

Table 3. Survey items.

\begin{tabular}{|c|c|}
\hline \multirow{3}{*}{ Personal characteristics } & $\begin{array}{l}\text { Age } \\
\text { Gender }\end{array}$ \\
\hline & Number of people in their household \\
\hline & Medical conditions \\
\hline \multirow{3}{*}{ Through assembly experiments of reflector kits } & Ease of assembly ratings \\
\hline & $\begin{array}{l}\text { Reasons indicated for rating kit assembly as } \\
\text { difficult. }\end{array}$ \\
\hline & $\begin{array}{c}\text { Participants' ideas of needs they made want to } \\
\text { communicate to response teams outside the } \\
\text { disaster area. } \\
\text { Sensitivity to reflector kit }\end{array}$ \\
\hline
\end{tabular}

Next, we had the participants rate the kit's ease of assembly as well as indicate specifically what they found difficult. As shown in Figure 4, the kit consists of a bottom plate and all the corner latches and partition plates necessary to make a 4-sided, 6-sided, or 9-sided reflector. We had the participants actually assemble all three types at their homes and rate the ease of assembly for each on a 4-point scale: "Very easy," "Easy," "Difficult," or "Very difficult." The ratings are shown in Figure 15. For each type, most participants indicated the assembly was difficult or very difficult. Moreover, the difficulty increased as the number of plates used increased.

As to what respondents found specifically difficult or very difficult for each type, the free responses are summarized in Figure 16. The most difficult step was snapping the top corner latch in place over the plates (the final step). This was the case for most of the respondents for every reflector type. The likely cause of this problem was that one or more of the plates had not been completely snapped into place into the holes in the bottom plate, so they were unstable. Inserting the plates into the bottom corner latch was indicated as a problem by one respondent for the 4-sided type and by two respondents for each of the other types, and other responses indicated that some participants had trouble snapping the plates into the holes in the bottom plate and others found that after snapping them in place they wobbled. Additional notable feedback obtained was that, for example, for each type, one respondent indicated they had trouble assembling the kit because they had to use both hands, and one respondent had trouble assembling it in a place that was not level. 
Table 4. Respondent demographics and medical conditions.

\begin{tabular}{|c|c|c|c|c|c|c|c|c|}
\hline \multirow[b]{2}{*}{ Age } & \multirow[b]{2}{*}{ Gender } & \multirow[b]{2}{*}{$\begin{array}{c}\text { Number of } \\
\text { Family }\end{array}$} & \multicolumn{3}{|c|}{ 1. Conditions } & \multicolumn{3}{|c|}{ 2. Conditions } \\
\hline & & & $\begin{array}{l}\text { Disease } \\
\text { Name }\end{array}$ & $\begin{array}{l}\text { Attending } \\
\text { Hospital }\end{array}$ & $\begin{array}{l}\text { Frequency } \\
\text { by Month }\end{array}$ & $\begin{array}{l}\text { Disease } \\
\text { Name }\end{array}$ & $\begin{array}{l}\text { Attending } \\
\text { Hosipital }\end{array}$ & $\begin{array}{l}\text { Frequency } \\
\text { by Month }\end{array}$ \\
\hline 73 & Male & 3 & Glaucoma & Yes & 0.5 & & & \\
\hline 65 & Male & 1 & & & & - & & \\
\hline 71 & Female & 1 & $\begin{array}{l}\text { High blood } \\
\text { pressure }\end{array}$ & Yes & 1 & & & \\
\hline 72 & Male & 2 & Gout & Yes & 0.5 & & & \\
\hline 72 & Female & 4 & Osteoporosis & Yes & 0.5 & & & \\
\hline 73 & Male & 2 & $\begin{array}{l}\text { Chronic } \\
\text { gastritis }\end{array}$ & Yes & 1 & Lumbago & Yes & 8 \\
\hline 66 & Male & 2 & $\begin{array}{c}\text { High blood } \\
\text { pressure }\end{array}$ & Yes & 1 & Gout & Yes & 1 \\
\hline 62 & Male & 1 & Hyperuricemia & Yes & 1 & Cholesterinemia & & \\
\hline 69 & Female & 2 & Gonarthrosis & Yes & 2 & & & \\
\hline 60 & Female & 1 & & & & - & & \\
\hline
\end{tabular}

4-sided reflector

\begin{tabular}{|l|l|}
\hline 4 & 6 \\
\hline
\end{tabular}

6-sided reflector

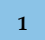

7

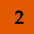

9-sided reflector

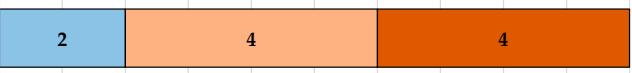

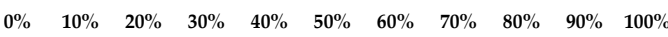

- Very easy $\square$ Easy $\square$ Difficult $\square$ Very difficult

Figure 15. Ease of assembly ratings.

Difficulty in inserting top corner latches

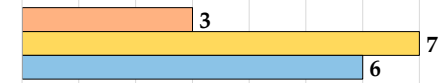

Difficulty in inserting bottom corner latches

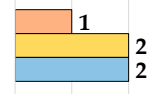

Difficult to insert the partition plates into bottom corner latches.

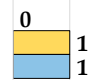

Partition plates are not stable

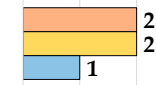

Many tasks require the use of both hands

trouble assembling it in a place that was not level

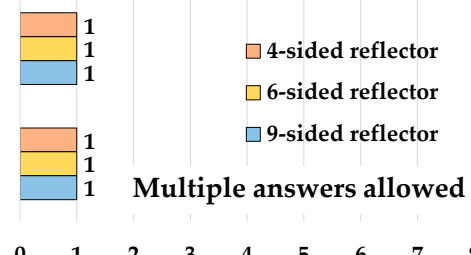

Figure 16. Reasons indicated for rating kit assembly as difficult. 
Next, we asked participants to rate their interest using the reflector kit in the event of a magnitude 7 earthquake to signal their location and needs to rescue teams outside of the disaster area using a 4-point scale: "Yes, very much," "Yes," "No," and "No, not at all." The overall response was positive, with 3 of the 10 responding "Yes, very much" and 7 responding "Yes."

Based on the survey responses from 10 of the participants, results showed that despite having some problems with the kit's assembly, they were interested in using the kit in the event of an earthquake. This suggests that it is essential that the assembly-related problems be remedied. The biggest problems were how difficult it was to snap the top corner latch into place and how unstable the partition plates were after being snapped into the holes in the bottom plate. A potential solution for the stability problem is to make the bottom plate thicker than the current $3.0 \mathrm{~mm}$ and to make the prongs that fit into the holes in the bottom plate longer. For the top corner latch issue, the material from which it is made could be changed to transparent plastic or some other material, which might make it easier to match the slits with the plates. In any case, an issue for further investigation will be how to improve the kit's ease of assembly.

Finally, using an open-ended question with a free response, we explored what participants thought they might need to communicate to response teams outside of the disaster area. We used our own judgment to categorize the responses, which are shown in Figure 17. The most frequent response (from nine respondents) was "To call for help if they or someone else was injured," followed by "To ask for food" (six respondents). "To communicate that they or someone else was safe" and "To ask for water" were mentioned by two participants each. The many other different needs they brought up included "To ask to be rescued due to the worsening of a chronic condition," "To ask for more medication," and "To report the failure of essential utilities and infrastructure (power, water, roads, etc.)."

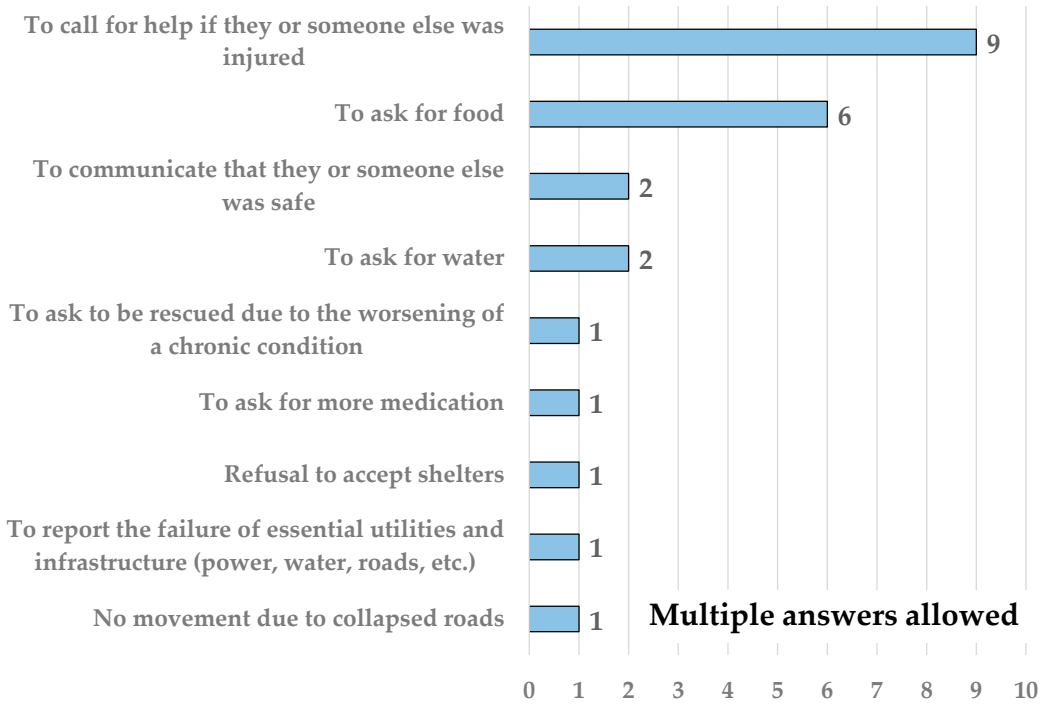

Figure 17. Participants' ideas of needs they made want to communicate to response teams outside the disaster area.

\section{Conclusions and Further Issues}

Results of the satellite observations confirmed that means \pm SDs for the backscattering coefficients for each type of reflector were discrete. This meant the type of reflector could be identified by calculating its backscattering coefficient, so it should be possible to use the reflector type to signal a specific type of need. What we plan to do in the future is to develop a mechanism to automatically detect the reflectors based on backscattering coefficients calculated from the SAR imagery data from observations. The presence of a reflector could be identified by comparing SAR images of the same area over time during 
an observation period of interest to detect the appearance of each reflector's "signature" as an abnormality.

In addition, although the feedback survey showed that the participants reported they would be interested in using the reflector in the event of an actual earthquake disaster, it also showed they felt they sometimes encountered problems with the kit assembly. We plan to make the necessary improvements, which, as explained, will require coming up with ways to improve some of the parts. Once the kit is improved, that should garner even more interest in its use. Furthermore, a questionnaire survey will be conducted in areas where earthquake disasters occurred in the past, to examine the people's needs. After that, the optimal pattern of needs will be determined through consultations with local governments and residents. Finally, given that only 10 participants responded to the survey in this study, in future studies we plan to try to increase the sample size and have more seniors test the assembly of the kits.

Author Contributions: Conceptualization, Y.M. and M.F.; methodology, Y.M. and M.F.; software, M.F.; validation, M.F. and J.T.; formal analysis, Y.M.; investigation, Y.M.; resources, R.F.; data curation, R.F.; writing—original draft preparation, Y.M.; writing—review and editing, M.F.; visualization, Y.M.; supervision, M.F. and J.T.; project administration, M.F.; funding acquisition, M.F. All authors have read and agreed to the published version of the manuscript.

Funding: This research received no external funding.

Data Availability Statement: Data sharing does not apply to this article.

Conflicts of Interest: The authors declare no conflict of interest.

\section{References}

1. Statistics Bureau of Japan. 5. International Comparisons of Statistics for the Elderly. Available online: https:/ /www.stat.go.jp/ data/topics/topi1135.html (accessed on 1 January 2021).

2. Cabinet Office Japan Disaster Management Information Page. Measures for People Requiring Assistance during a Disaster. Available online: http:/ / www.bousai.go.jp/taisaku/hisaisyagyousei/youengosya/ (accessed on 1 January 2021).

3. Morisaki, Y.; Fujiu, M.; Furuta, R.; Takayama, J. Evaluation of methods of understanding vulnerable people's needs after large scale earthquake disaster. J. Japan Soc. Civil Eng. D3 2021, 76, 259-266. (In Japanese)

4. Reflector-Identification System. Japanese Patent Application No. 2020-128207, 2 August 2019. patent pending.

5. Miura, H.; Midorikawa, S.; Matsuoka, M. Accuracy improvement of building damage detection using high-resolution SAR images observed from different directions. J. Japan Assoc. Earthq. Eng. 2015, 15, 390-403. (In Japanese)

6. Hasekura, K.; Gokon, H.; Koshimura, S.; Meguro, K. Verification of a method for determining analysis area of building damage in a tsunami affected area by using L-band SAR data. J. Soc. Saf. Sci. 2016, 29, 47-52. (In Japanese)

7. Sato, H.; Miyahara, B.; Okatani, T.; Koarai, M.; Sekiguchi, T.; Yagi, H. Detection of landslide surface deformation triggered by the 2011 off the Pacific coast of Tohoku earthquake using InSAR image. J. Jpn. Landslide Soc. 2014, 51, 41-49. (In Japanese) [CrossRef]

8. Li, C.; Zhang, G.; Shan, X.; Zhao, D.; Li, Y.; Huang, Z.; Jia, R.; Li, J.; Nie, J. Surface Rupture Kinematics and Coseismic Slip Distribution during the 2019 Mw7.1 Ridgecrest, California Earthquake Sequence Revealed by SAR and Optical Images. Remote Sens. 2020, 12, 3883. [CrossRef]

9. Takahashi, T.; Usui, T.; Fujishima, T.; Ohki, M.; Sano, H.; Kosada, H. Education using ALOS-2 with easy-to-make reflectors. J. Remote Sens. Soc. Jpn. 2016, 36, 360-366. (In Japanese)

10. Suzuki, H. Studies on the development of citizen participation geoglyphs production programs using earth observation satellite. Bull. Kanazawa Coll. Art 2016, 60, 33-58. (In Japanese)

11. Jauvin, M.; Yan, Y.; Trouvé, E.; Fruneau, B.; Gay, M.; Girard, B. Integration of Corner Reflectors for the Monitoring of Mountain Glacier Areas with Sentinel-1 Time Series. Remote Sens. 2019, 11, 988. [CrossRef]

12. Schmidt, K.; Reimann, J.; Tous Ramon, N.; Schwerdt, M. Geometric Accuracy of Sentinel-1A and 1B Derived from SAR Raw Data with GPS Surveyed Corner Reflector Positions. Remote Sens. 2018, 10, 523. [CrossRef]

13. Osaragi, T.; Oki, T. A real time synchronous system for collecting, sharing, and utilizing disaster information. J. Archit. Plan. 2017, 82, 2451-2459. (In Japanese) [CrossRef]

14. Hiruta, M.; Tsuruoka, Y.; Tada, Y. A proposal of a disaster information sharing system. IEICE Tech. Rep. 2012, 2, 5-8. (In Japanese)

15. Jeong, B.; Zama, S.; Takizawa, O.; Endo, M.; Shibayama, A. Development of a disaster damage information collecting system using cellular phone. J. Japan Assoc. Earthq. Eng. 2009, 9, 2_102-2_112. (In Japanese)

16. Sugii, K.; Sekizawa, A.; Okabe, H.; Endo, M.; Zama, S.; Araiba, K. Necessity of structuring an effective scheme of acquiring disaster information by fire departments just after an earthquake. J. Soc. Saf. Sci. 2008, 10, 89-96. (In Japanese) 
17. Remote Sensing Technology Center of Japan: ASNARO-2. Available online: https://www.restec.or.jp/satellite/asnaro-2 (accessed on 1 January 2021).

18. Kanazawa City: Population/Number of Households (Updated Monthly). Available online: https://www4.city.kanazawa.lg.jp/ 11018/toukeidatasyu/jinnkousetaisu.html (accessed on 1 January 2021). 